\title{
Downscaling land use and land cover from the Global Change Assessment Model for coupling with Earth system models
}

\author{
Yannick Le Page ${ }^{1,2}$, Tris O. West ${ }^{1}$, Robert Link ${ }^{1}$, and Pralit Patel ${ }^{1}$ \\ ${ }^{1}$ Centro de Estudos Florestais, Instituto Superior de Agronomia, Universidade de Lisboa Department Tapada da Ajuda, \\ 1349-017 Lisbon, Portugal \\ ${ }^{2}$ Pacific Northwest National Laboratory, Joint Global Change Research Institute, University of Maryland, College Park, \\ MD 20740, USA
}

Correspondence to: Yannick Le Page (niquya@gmail.com)

Received: 4 April 2016 - Published in Geosci. Model Dev. Discuss.: 23 May 2016

Revised: 5 August 2016 - Accepted: 10 August 2016 - Published: 2 September 2016

\begin{abstract}
The Global Change Assessment Model (GCAM) is a global integrated assessment model used to project future societal and environmental scenarios, based on economic modeling and on a detailed representation of food and energy production systems. The terrestrial module in GCAM represents agricultural activities and ecosystems dynamics at the subregional scale, and must be downscaled to be used for impact assessments in gridded models (e.g., climate models). In this study, we present the downscaling algorithm of the GCAM model, which generates gridded time series of global land use and land cover (LULC) from any GCAM scenario. The downscaling is based on a number of user-defined rules and drivers, including transition priorities (e.g., crop expansion preferentially into grasslands rather than forests) and spatial constraints (e.g., nutrient availability). The default parameterization is evaluated using historical LULC change data, and a sensitivity experiment provides insights on the most critical parameters and how their influence changes regionally and in time. Finally, a reference scenario and a climate mitigation scenario are downscaled to illustrate the gridded land use outcomes of different policies on agricultural expansion and forest management. Several features of the downscaling can be modified by providing new input data or changing the parameterization, without any edits to the code. Those features include spatial resolution as well as the number and type of land classes being downscaled, thereby providing flexibility to adapt GCAM LULC scenarios to the requirements of a wide range of models and applications. The downscaling system is version controlled and freely available.
\end{abstract}

\section{Introduction}

Land use and land cover (LULC) change is a key component of environmental change studies. More than $50 \%$ of the terrestrial biosphere has now been transformed to urban areas, croplands, or rangelands by anthropogenic activities (Ellis, 2011). Estimates of the carbon budget from historical LULC change range from 12.5 to $33 \%$ of all anthropogenic carbon emissions depending on the time period and method considered (Houghton et al., 2012). These emissions combined to LULC-induced albedo and moisture dynamic alterations are a significant - albeit poorly constrained - climate forcing (e.g., Brovkin et al., 2013; Mahmood et al., 2010; Pongratz et al., 2010). The array of LULC change impacts extends to many other environmental aspects, including biodiversity, freshwater resources, and air quality (Foley et al., 2005), hence the importance of projecting future land use scenarios for impacts assessments.

The Global Change Assessment Model (GCAM) has been developed to better understand interactions between natural and human systems and anticipate their co-evolution in the future. It combines representations of the global economy, energy systems, agriculture, and land use with a representation of terrestrial, ocean and atmospheric biogeochemical cycles, ice-melt, and climate processes (Clarke et al., 2007; Kim et al., 2006). GCAM is extensively used to explore the direct effects of changes in exogenous assumptions, such as population, technology, yield improvements, economic and environmental policies, as well as their system-wide repercussions. These analyses are performed using GCAM as a 
stand-alone model or coupled to specialized models with greater capabilities for impact assessments. For example, GCAM provided greenhouse gas emissions and LULC projections for one of the four scenarios of the IPCC 5th Assessment Report, the Representative Concentration Pathway 4.5 (RCP4.5, Thomson et al., 2011). Those data were used as inputs to climate models to generate climate projections and perform a wide range of impact, adaptation, and vulnerability assessments (Pachauri et al., 2014).

Coupling models involves adapting the data and models so that the flow of information is consistent with the source model and can be assimilated by the destination model. In the case of GCAM, spatial resolution is a technical challenge for coupling studies looking at the impacts of LULC change. GCAM represents these dynamics at subregional scale while Earth system models and regional natural resource (i.e., agriculture and forestry) models typically operate at gridded scales. For example, the U.S. is divided into eight agroecological zones (AEZs, Monfreda et al., 2009) of various sizes (up to 2.5 million $\mathrm{km}^{2}$ ) and shapes. GCAM tracks the share of land categories in each AEZ, but not where they are actually located within each zone. This issue was addressed for the IPCC 5th Assessment Report with a downscaling algorithm designed specifically for coupling to climate models (Hurtt et al., 2011). However, gridded LULC scenarios are needed for a variety of models and applications, each requiring specific data attributes (e.g., resolution, land categories, management practices, Kraucunas et al., 2014). A flexible downscaling component within the GCAM modeling framework is thus needed to meet these multiple applications.

This paper presents LULC downscaling capabilities, code, and parameters developed for the GCAM model. An evaluation analysis with historical land use data is performed to quantify the spatial accuracy of land use change allocation, and a sensitivity analysis is conducted to identify critical parameters. Finally, the downscaling method is applied to scenarios of future land use change projected by GCAM, generating gridded land use projections that can be used for impact assessments in coupling experiments.

\section{Overview of the GCAM model}

GCAM is global in scope and spatially disaggregated into geopolitical regions that interact through international trade. GCAM computes supply, demand, and prices in 5-year intervals for a variety of primary energy carriers, secondary energy carriers, and agricultural and forest products. Economic behavior in GCAM is determined as a result of markets in which the supplies and demands for economic goods and services are assumed to clear on the model's time step. As supplies and demands shift in GCAM's regions, market clearing prices change as do production, consumption, and trade patterns.

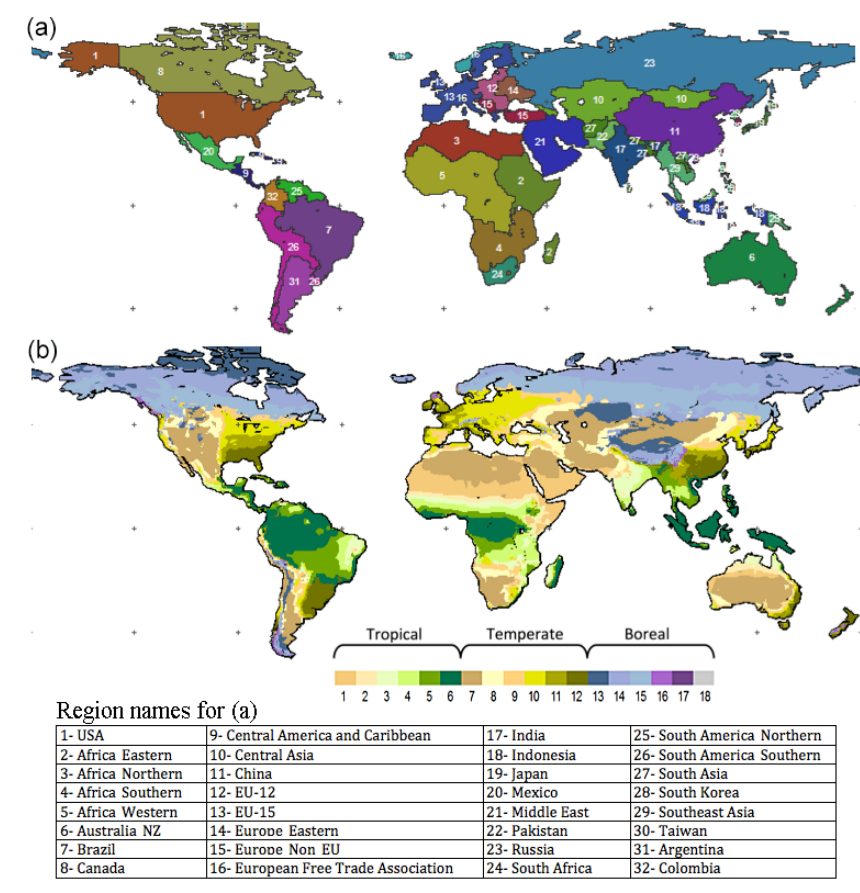

Figure 1. (a) 32 GCAM regions. (b) Agroecological zones (AEZs).

The terrestrial system is represented in GCAM to account for its role in food, wood, energy production (Calvin et al., 2014), and in the carbon and water cycles (Hejazi et al., 2014; Le Page et al., 2013), providing capabilities to explore interactions and the implications of environmental policies (Fig. S1 in the Supplement, Kraucunas et al., 2014; Thomson et al., 2011). While we focus here on describing the spatial scale and land types in GCAM because they are essential aspects for the downscaling, a more technical description of the terrestrial module is available in the literature (Kyle et al., 2011; Wise et al., 2014; Wise and Calvin, 2011).

GCAM represents the world terrestrial biosphere into 283 spatial units, the result of the intersection of two spatial scales. First, the world countries are aggregated into 32 geopolitical and socioeconomic regions (Fig. 1a), a scale at which most economic sectors are represented (e.g., industrial production, energy use, trade, and natural resources). Second, global land area is split into 18 agroecological zones (AEZs, Fig. 1b) to represent natural ecosystems and agricultural activities, providing a climate-based zoning to better account for vegetation and crop productivity. These $18 \mathrm{AEZs}$ are intersected with the 32 regions to get the 283 unique combinations of region and AEZ.

Each of these 283 region/AEZ can have up to 22 types of land cover: 5 types of natural ecosystems and 17 types of managed lands (Table 1). Initial land areas for the first GCAM time step (2005) are inferred from the History Database of the Global Environment (HYDE, Klein Goldewijk et al., 2011), the FAO RESOURCESTAT database (FAO, 2010), and potential vegetation data (Ramankutty and 
Table 1. Terrestrial land types in GCAM.

\begin{tabular}{ll}
\hline Natural land & Forests, shrublands, grasslands, tundra, deserts \\
\hline Managed land & $\begin{array}{l}\text { Corn, wheat, rice, root \& tubers, oil crops, sugar crops, other grain crops, fiber crops, fodder } \\
\text { grass, fodder herb, biomass crops, miscellaneous crops, other arable land (e.g., fallow), palm } \\
\text { fruit, pasture, urban, willow, managed forest }\end{array}$ \\
\hline
\end{tabular}

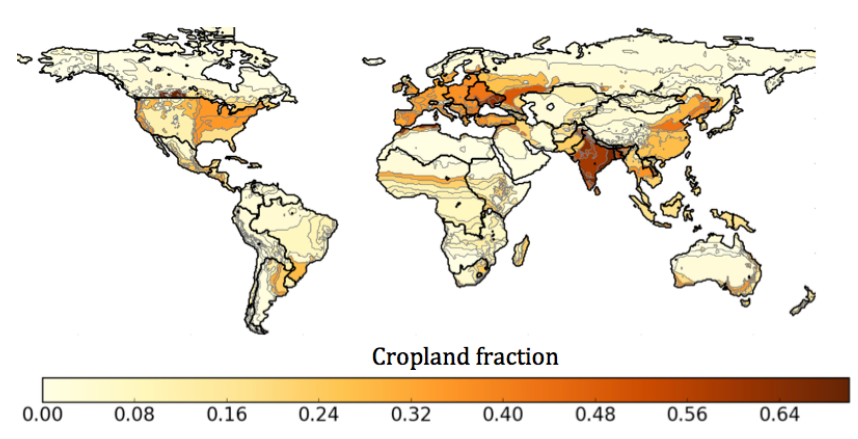

Figure 2. Distribution of 2005 GCAM croplands at the region/AEZ scale. The algorithm presented in this paper downscales these patterns to a gridded scale (Figs. 5 and 7).

Foley, 1999a), as detailed in Kyle et al. (2011). For future time steps, GCAM integrates a range of drivers to determine LULC change, including food demand (population growth, diet changes), region/AEZ-level crop productivity and costs (e.g., labor, fertilizer), energy demand (bioenergy crops), and environmental policies, among others. A major application of GCAM consists in exploring LULC projections under alternative configurations of these drivers (Calvin et al., 2014; Thomson et al., 2010, 2011). For example, while the reference scenario projects continuing deforestation and expansion of global agriculture in response to growing food demand, implementing a terrestrial carbon market shifts the economics of land use decisions towards agriculture intensification and afforestation. These scenarios are depicted at the region/AEZ scale, as illustrated in Fig. 2 for croplands, but can be gridded with the downscaling algorithm detailed below.

\section{Downscaling algorithm}

The GCAM LULC downscaling method is based on previous work by West et al. (2014) at the national scale for the U.S. It consists of allocating tabular land areas from a relatively coarse set of spatial units to a higher-resolution land cover grid (West et al., 2010). In the case of GCAM, these spatial units are defined by the intersection between regions and AEZs (Fig. 1), and the resolution of the final grid for the global analysis presented here is $0.25^{\circ}(\sim 28 \mathrm{~km}$ at the equator). The algorithm relies on gridded observations of LULC and on a set of user-defined rules to spatially allocate land types within each region/AEZ (Fig. 3).

The algorithm starts with a preprocessing phase of the GCAM and observation-derived gridded LULC data to harmonize their attributes. It is labeled the reconciliation phase, and consists of (1) aligning total land areas of each region/AEZ from both data sources and (2) converting their respective land schemes to a common set of land types that are ultimately downscaled.

Following data reconciliation, the actual downscaling is performed. The algorithm starts in the base year (first time step, e.g., 2005), and modifies the observed gridded data until land shares in each region/AEZ are equal to the shares in the GCAM model. If a given region/AEZ has $100 \mathrm{~km}^{2}$ of crops in GCAM but only $80 \mathrm{~km}^{2}$ in the observation, $20 \mathrm{~km}^{2}$ of crops will be created by converting other land types that are in excess. The geospatial allocation of the additional $20 \mathrm{~km}^{2}$ of cropland depends on a number of downscaling rules that are described in the next sections, including land use transition priorities and spatial constraints (e.g., nutrient availability for agriculture). Once completed, the base-year downscaled data consists in gridded LULC that is consistent with GCAM at the region/AEZ scale with spatial patterns similar to observed LULC (Fig. 3). This gridded GCAM LULC in the base year then becomes the starting point to which LULC change of the following time step is attributed, following the same downscaling rules. This process is repeated for each time step until the entire scenario is downscaled (e.g., 20052100).

The next sections describe the code and its user-defined parameters in more details. For the sake of clarity, it is based on a relatively simple configuration of the downscaling, referred to as "default configuration", but many aspects are flexible as specified in the text. The spatial LULC data used in the default configuration are from the MODIS MCD12Q1 version 5.1 product for the year 2005, PFT Type 5 classification (Friedl et al., 2010), aggregated from $500 \mathrm{~m}$ to $0.25^{\circ}$ resolution.

\subsection{Reconciliation phase}

\subsubsection{Matching land areas}

Although the downscaling aims at maintaining consistency with the original GCAM land outputs, the total land area in each region/AEZ has to be adjusted to match the observation data. Otherwise, expansion on water (case of more land in 


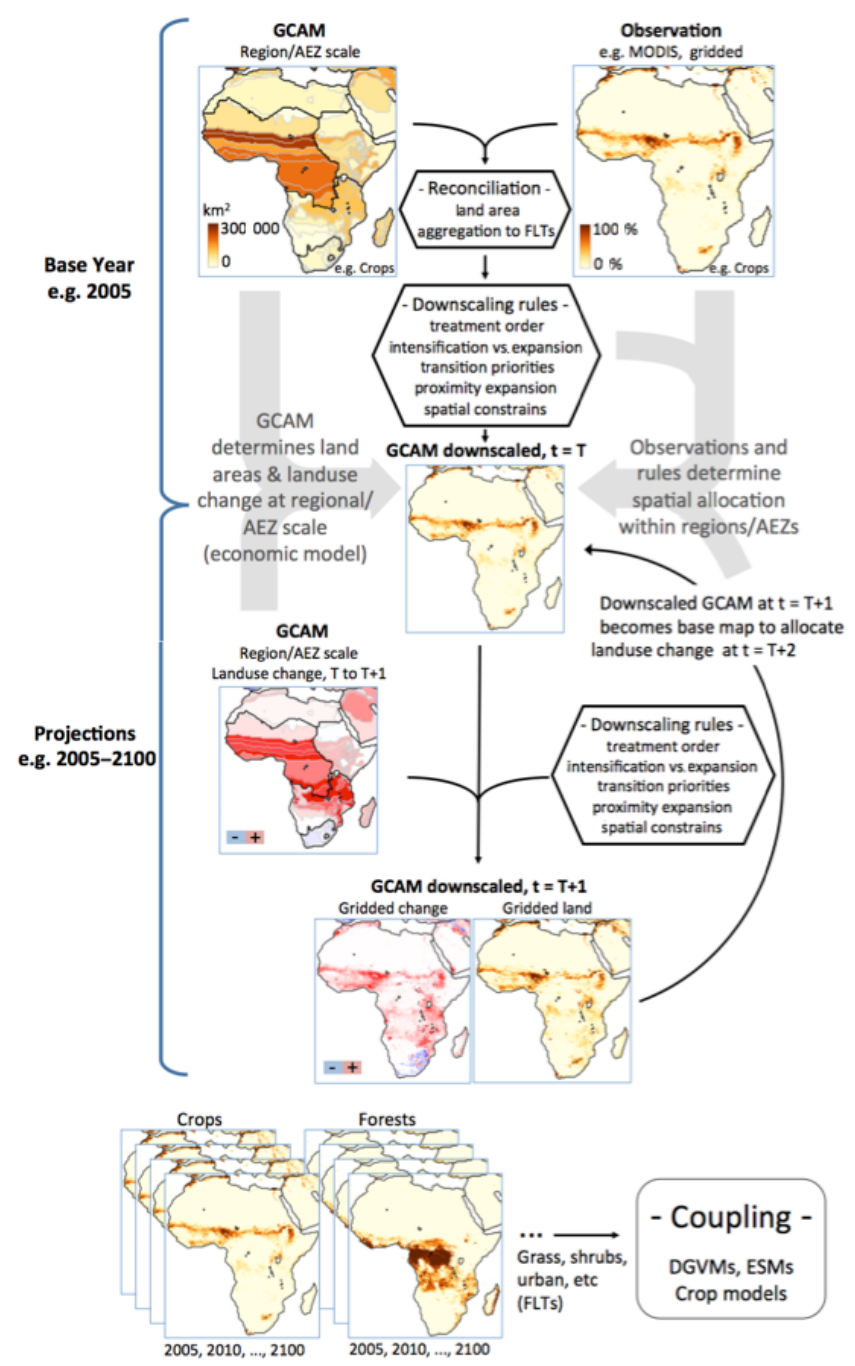

Figure 3. Overview of the downscaling method. The figure shows the successive computational steps to downscale a LULC change scenario from 2005 to 2100 described in the text (Sect. 3). The reconciliation phase is detailed in Sect. 3.1; The downscaling rules are detailed in Sect. 3.2, including the treatment order (Sect. 3.2.1), intensification vs. expansion ratio (Sect. 3.2.2), the transition priorities (Sect. 3.2.3), and the spatial constrains (Sect. 3.2.4).

GCAM) and removal of observed terrestrial land (case of less land) would be necessary, which was considered unrealistic. All GCAM land types (GLTs) are adjusted by the same ratio within a given region/AEZ:

$A_{R, Z, L}^{\mathrm{GC}}=A_{R, Z, L}^{\mathrm{G}} \times \frac{A_{R, Z}^{\mathrm{O}}}{A_{R, Z}^{\mathrm{G}}}$,

where $A^{\mathrm{G}}$ and $A^{\mathrm{O}}$ are the GCAM and observed areas, $A^{\mathrm{GC}}$ the final, adjusted GCAM areas, $R$ and $Z$ the region/AEZ, and $L$ the GCAM land type considered. When compared to MODIS, the total area of most regions/AEZs differs by less than $3 \%$. Globally, total land area is 126.9 million $\mathrm{km}^{2}$ in GCAM and 128.1 million $\mathrm{km}^{2}$ in MODIS (not including small islands and other territories that are not represented in GCAM and thus remain equal to observations throughout the downscaling).

\subsubsection{Aggregation to common land type categories}

Once total land areas are the same, both the GCAM and spatial land types (GLTs and SLTs) are aggregated to a common scheme of final land types (FLTs). For example, the MODIS data have only one cropland type, while GCAM has 13 different types. All GCAM crop types are thus aggregated to a single crop category to enable the downscaling: if GCAM corn was kept as an individual land type, there would be no indication of where those corn crops should be allocated from the MODIS data. In the default configuration, the common scheme includes seven FLTs: forests, shrubs, grass, crops, urban land, snow, and sparse vegetation.

Aggregation of the spatial data is user defined with an input table (Table 2). For a given SLT, a number from 0 to 1 determines the share of that land type that goes to each of the FLTs. Typically, the share is either 0 or 1 , meaning that an SLT is entirely attributed to a single FLT (Table 2). However, some land cover classification products include mixed land types (e.g., mosaic of crops and forests). In such a case, the area under that type could be split into crops and forests by using shares of 0.5 .

Aggregation of the GCAM data at the region/AEZ scale follows the same concept (Table 3), only with a different approach when a given GLT has to be split into 2 or more FLTs: the shares received by each FLT are determined by the spatial data in that region/AEZ. For example, the GLT RockIceDesert can qualify to both the snow and the sparse FLTs. However, the fraction that should go to each depends on the region/AEZ considered: most would go to snow in Greenland and to sparse in central Australia. The table is thus filled with the number 1 for both (Table 3 ) to indicate that this GLT needs to be split, and the code computes the actual split as the share of snow and sparse seen in the spatial data (e.g., MODIS) for each region/AEZ.

\subsection{Downscaling rules}

Once the GCAM and spatial data are reconciled and aggregated to the same land type categories (i.e., FLTs), downscaling is performed based on a set of user-defined rules: a treatment order defining which FLTs are downscaled first, an intensification vs. expansion ratio, transition priorities defining what type of land swaps are favored, and spatial constraints which attribute to each grid cell a likelihood to receive an expanding FLT. All these rules influence the spatial patterns of the final downscaled GCAM data (see sensitivity analysis in Sect. 4). 
Table 2. User-defined aggregation of the spatial data. Spatial land types (SLTs, rows) are attributed to the final land types (FLTs, columns) identified by the number 1. For example, all MODIS forest types are here attributed to the forest FLT. Numbers between 0 and 1 can be used to aggregate a given SLT into several FLTs (e.g., a mosaic of crops and forests SLT could be split into the forest and crop FLTs using the values 0.5; see Sect. 3.1.2).

\begin{tabular}{lrrrrrrr}
\hline \multirow{2}{*}{ Spatial land types (SLTs, MODIS) } & \multicolumn{7}{c}{ Final land types (FLTs) for downscaling } \\
\cline { 2 - 8 } & Forest & Shrub & Grass & Crops & Urban & Snow & Sparse \\
\hline Ev. needl. forest & 1 & 0 & 0 & 0 & 0 & 0 & 0 \\
Ev. broad. forest & 1 & 0 & 0 & 0 & 0 & 0 & 0 \\
Dec. needl. forest & 1 & 0 & 0 & 0 & 0 & 0 & 0 \\
Dec. broad. forest & 1 & 0 & 0 & 0 & 0 & 0 & 0 \\
Shrub & 0 & 1 & 0 & 0 & 0 & 0 & 0 \\
Grass & 0 & 0 & 1 & 0 & 0 & 0 & 0 \\
Crops & 0 & 0 & 0 & 1 & 0 & 0 & 0 \\
Urban & 0 & 0 & 0 & 0 & 1 & 0 & 0 \\
Snow & 0 & 0 & 0 & 0 & 0 & 1 & 0 \\
Sparse & 0 & 0 & 0 & 0 & 0 & 0 & 1 \\
\hline
\end{tabular}

\subsubsection{Treatment order}

The algorithm downscales all FLTs one after the other; an order thus has to be defined. The input files include a table where users specify that order (Table 4).

\subsubsection{Intensification vs. expansion ratio}

When the GCAM projections indicate that the area of a given FLT is increasing, the additional area can be downscaled on grid cells where the FLT already exists, which is referred to as intensification, or on grid cells where it does not yet exist, referred to as expansion. In the real world, the ratio of intensification vs. expansion varies in space and time. In North America, for example, land giveaways, infrastructure development, and a number of other factors led to a large-scale westward expansion of agricultural activities from 1800 to 1950, then to their intensification until today, with most of the Corn Belt now featuring more than $80 \%$ crop cover (Ramankutty and Foley, 1999b). In the default configuration presented here, the intensification ratio (intens_ratio) is set to 0.8 globally, and is part of the sensitivity analysis (Sect. 3). The code can be modified to define specific ratios for different regions or time periods, however. Note that the ratio is a target, which sometimes cannot be met. In the extreme case where croplands exist in all grid cells of a region/AEZ, for example, expansion is impossible. The code then applies the desired expansion target as intensification instead.

\subsubsection{Transition priorities}

At each time step, GCAM computes LULC change at the region/AEZ scale, but does not give any indication on land use transitions. For example, if crops and forests increase while shrubs and grass decrease, the share of each possible conversion - or transition - is not known (shrubs to crops, grass to crops, shrubs to forests, grass to forests). It is, however, an aspect we have to represent when downscaling LULC change to a spatial grid, and is also relevant information for Earth system modelers (see Discussion). A preference order for land use transitions is thus user defined in the parameter files, for each FLT (Table 5). In the default configuration, crops are set to preferentially replace urban land, then grasslands, then shrublands, then forests, etc. This is a preference only: specific transitions can only happen if the FLT to be converted is projected to decrease in GCAM. In the example given above, crops could not be increased into forested land because forests are also projected to increase. This is related to the concepts of net vs. gross LULC change (see Discussion).

\subsubsection{Spatial constraints}

Any kind of spatial constraints can be used to influence the downscaling. For a constraint to be implemented, users must provide the input data at the resolution considered and parameterize its influence. The input data must be bound from 0 (fully constraining) to 1 (no constraint). Then, the parameterization defines the relative contribution of that specific constraint in influencing the downscaling, and is specific to each FLT. In the default configuration illustrated in Table 6, three spatial constraints are listed: kernel density, soil workability, and nutrient availability.

Kernel density represents the proximity and density of a given FLT around a given grid cell. It is computed by default in the code, adjusting to the new FLT distribution at each time step. It was implemented under the assumption that new areas of a given FLT tend to appear close to where it already is (e.g., desertification and crop expansion around agricultural areas). This is defined by 
Table 3. User-defined aggregation of the GCAM data. GCAM land types (GLTs, rows) are attributed to the final land types (FLTs, columns) identified by the number 1 . Several $1 \mathrm{~s}$ in the same row means that the considered GLT will be split into the corresponding FLTs. For example, the RockIceDesert GLT is here aggregated into the snow and sparse FLTs. The actual share of the GLT going to each FLT is determined for each region/AEZ based on the share of those FLTs in the spatial data (see Sect. 3.1.2).

\begin{tabular}{lrrrrrrr}
\hline GCAM land types (GLTs) & \multicolumn{7}{c}{ Final land types (FLTs) for downscaling } \\
\cline { 2 - 7 } & Forest & Shrub & Grass & Crops & Urban & Snow & Sparse \\
\hline Corn & 0 & 0 & 0 & 1 & 0 & 0 & 0 \\
Wheat & 0 & 0 & 0 & 1 & 0 & 0 & 0 \\
Rice & 0 & 0 & 0 & 1 & 0 & 0 & 0 \\
Root_Tuber & 0 & 0 & 0 & 1 & 0 & 0 & 0 \\
OilCrop & 0 & 0 & 0 & 1 & 0 & 0 & 0 \\
SugarCrop & 0 & 0 & 0 & 1 & 0 & 0 & 0 \\
OtherGrain & 0 & 0 & 0 & 1 & 0 & 0 & 0 \\
FiberCrop & 0 & 0 & 0 & 1 & 0 & 0 & 0 \\
FodderGrass & 0 & 0 & 0 & 1 & 0 & 0 & 0 \\
FodderHerb & 0 & 0 & 0 & 1 & 0 & 0 & 0 \\
Biomass & 0 & 0 & 0 & 1 & 0 & 0 & 0 \\
MiscCrop & 0 & 0 & 0 & 1 & 0 & 0 & 0 \\
OtherArableLand & 0 & 0 & 0 & 1 & 0 & 0 & 0 \\
PalmFruit & 0 & 0 & 0 & 1 & 0 & 0 & 0 \\
Pasture & 0 & 0 & 1 & 0 & 0 & 0 & 0 \\
UnmanagedPasture & 0 & 0 & 1 & 0 & 0 & 0 & 0 \\
UrbanLand & 0 & 0 & 0 & 0 & 1 & 0 & 0 \\
Willow & 1 & 0 & 0 & 0 & 0 & 0 & 0 \\
Forest & 1 & 0 & 0 & 0 & 0 & 0 & 0 \\
UnmanagedForest & 1 & 0 & 0 & 0 & 0 & 0 & 0 \\
Shrubland & 0 & 1 & 0 & 0 & 0 & 0 & 0 \\
Grassland & 0 & 0 & 1 & 0 & 0 & 0 & 0 \\
Tundra & 0 & 0 & 1 & 0 & 0 & 0 & 0 \\
RockIceDesert & 0 & 0 & 0 & 0 & 0 & 1 & 1 \\
\hline & & & & & & & \\
\hline
\end{tabular}

Table 4. User-defined treatment order.

\begin{tabular}{lr}
\hline $\begin{array}{l}\text { Final land } \\
\text { types (FLTs) }\end{array}$ & $\begin{array}{r}\text { Treatment } \\
\text { order }\end{array}$ \\
\hline Forest & 5 \\
Shrub & 7 \\
Grass & 6 \\
Crops & 4 \\
Urban & 1 \\
Snow & 2 \\
Sparse & 3 \\
\hline
\end{tabular}

$\mathrm{KD}_{\mathrm{FLT}}=\frac{1}{n} \times \sum_{\mathrm{gc}=1}^{n} \frac{F_{\mathrm{FLT}, \mathrm{gc}}}{\left(D_{\mathrm{gc}},\right)^{2}}$

where $\mathrm{KD}$ is the kernel density, $n$ the number of neighboring grid cells included in the computation, $F_{\mathrm{FLT}}$ the fraction of the FLT in the grid cell considered, and $D$ the distance of that grid cell to the grid cell for which the kernel density is being computed. A user-defined parameter - radius - represents the size of the moving window used to compute KD for each grid cell, thus controlling the number $n$. Note that the kernel density depends on land types in the surrounding grid cells, thus has a different influence on the downscaling than intensification, which is activated based on the considered grid cell only.

Soil workability and nutrient availability are two indicators of agricultural suitability from the Harmonized World Soil Database (HWSD, Fischer et al., 2008). In Table 6, kernel density contributes $100 \%$ of the spatial constrain for all FLTs except for crops, for which it contributes $40 \%$ while nutrient availability contributes $40 \%$ and soil workability the remaining $20 \%$. Note that the parameterization can include negative numbers to indicate that a constraint has the opposite influence: one could, for example, favor desertification in low-nutrient areas by having a negative value in the cell at the intersection of the nutrient availability row and sparse column in Table 6. Based on those spatial constraints contributions, each grid cell is attributed an index $S$ from 0 to 1 assessing how suitable they are to receive the considered FLT. In the case of crops and the default configuration 
Table 5. User-defined transition priorities.

\begin{tabular}{lrrrrrrr}
\hline \multirow{2}{*}{ Final land types (FLTs) } & \multicolumn{7}{c}{ Final land types (FLTs) for downscaling } \\
\cline { 2 - 8 } & Forest & Shrub & Grass & Crops & Urban & Snow & Sparse \\
\hline Forest & 0 & 1 & 2 & 3 & 4 & 6 & 5 \\
Shrub & 5 & 0 & 4 & 6 & 1 & 3 & 2 \\
Grass & 6 & 5 & 0 & 4 & 1 & 3 & 2 \\
Crops & 4 & 3 & 2 & 0 & 1 & 6 & 5 \\
Urban & 5 & 3 & 2 & 4 & 0 & 6 & 1 \\
Snow & 6 & 5 & 4 & 3 & 2 & 0 & 1 \\
Sparse & 6 & 4 & 2 & 3 & 5 & 1 & 0 \\
\hline
\end{tabular}

Table 6. User-defined spatial constrains.

\begin{tabular}{lrrrrrrr}
\hline Spatial constrains & \multicolumn{7}{c}{ Final land types (FLTs) for downscaling } \\
\cline { 2 - 8 } & Forest & Shrub & Grass & Crops & Urban & Snow & Sparse \\
\hline Kernel density & 100 & 100 & 100 & 40 & 100 & 100 & 100 \\
Soil workability & 20 & 20 & 20 & 20 & 20 & 20 & 20 \\
Nutrient availability & 0 & 0 & 0 & 40 & 0 & 0 & 0 \\
\hline
\end{tabular}

$$
\begin{aligned}
S= & \frac{40}{|40+40+20|} \times \mathrm{KD}+\frac{40}{|40+40+20|} \\
& \times \mathrm{NA}+\frac{20}{|40+40+20|} \times \mathrm{SW},
\end{aligned}
$$

where KD is the kernel density, NA the nutrient availability, and SW the soil workability, the relative contributions of which (40,40, and 20, respectively) are specified in Table 6. Each spatial constrain being a dimensionless index bound from 0 to 1 , the suitability index is dimensionless as well.

\subsection{Computational flow and implementation of the downscaling rules to allocate land use change}

A stylized overview of the code structure is shown in Fig. 4. Not included in this overview are a number of functions which can be activated in the user-input files to perform optional tasks such as mapping FLT distributions, saving statistics and converting the output data (.csv files by default) to netcdf format. A breakdown of run time and output sizes as a function of resolution, number of FLTs, and optional tasks activated are provided in the user manual. Downscaling all 5year time steps of a $2005-2100$ scenario at $0.25^{\circ}$ resolution with seven FLTs takes a few minutes on a standard desktop computer and produces around $100 \mathrm{MB}$ of output data when all optional tasks are turned off.

To better illustrate how the downscaling is actually computed, we provide a specific example: in a given region/AEZ, crops are projected by GCAM to increase by $100 \mathrm{~km}^{2}$ from 2015 to 2020, while grasslands and forests decrease by 70 and $30 \mathrm{~km}^{2}$, respectively. All other FLTs remain unchanged.
Of the $100 \mathrm{~km}^{2}$ cropland increase, $80 \mathrm{~km}^{2}$ are set to occur as intensification and $20 \mathrm{~km}^{2}$ as expansion (user-defined intensification vs. expansion ratio of 0.8; see Sect. 3.2.2).

The code goes through the first intensification loop (Fig. 4), following the treatment order (Table 4). Urban, snow, and sparse land types are skipped as they remain unchanged; then the loop goes to crops, which have to be intensified by $80 \mathrm{~km}^{2}$. The code thus goes through the land use transition priorities for crops (Table 5), starting with urban land, which does not have any area to spare and therefore remains unchanged. The second priority is grass, which does have land to spare as it is projected to decrease by $70 \mathrm{~km}^{2}$. All grid cells in that region/AEZ containing both crops and grass (intensification is for grid cells which already have crops) are thus selected, and their suitability index ( $S$, Sect. 3.2.4) is computed. Assuming that the more suitable a grid cell the more intensification it will receive, the $70 \mathrm{~km}^{2}$ of potential conversion are tentatively distributed to the selected grid cells according to their suitability index:

$\mathrm{TC}_{\mathrm{gc}}=70 \mathrm{~km}^{2} \times \frac{S_{\mathrm{gc}}}{\sum_{\mathrm{gcs}} S,}$

where TC stands for tentative conversion, gc the grid cell, and gcs the group of grid cells selected because they contain both crops and grass. The actual conversion is the minimum value between TC and the area of grass on each grid cell:

$\mathrm{AC}=\min (\mathrm{TC} \mid \mathrm{GA})$,

where AC stands for actual conversion and GA for grass area. Given that the tentative conversion might not be possible because the existing grass area is lower, the total conversion 


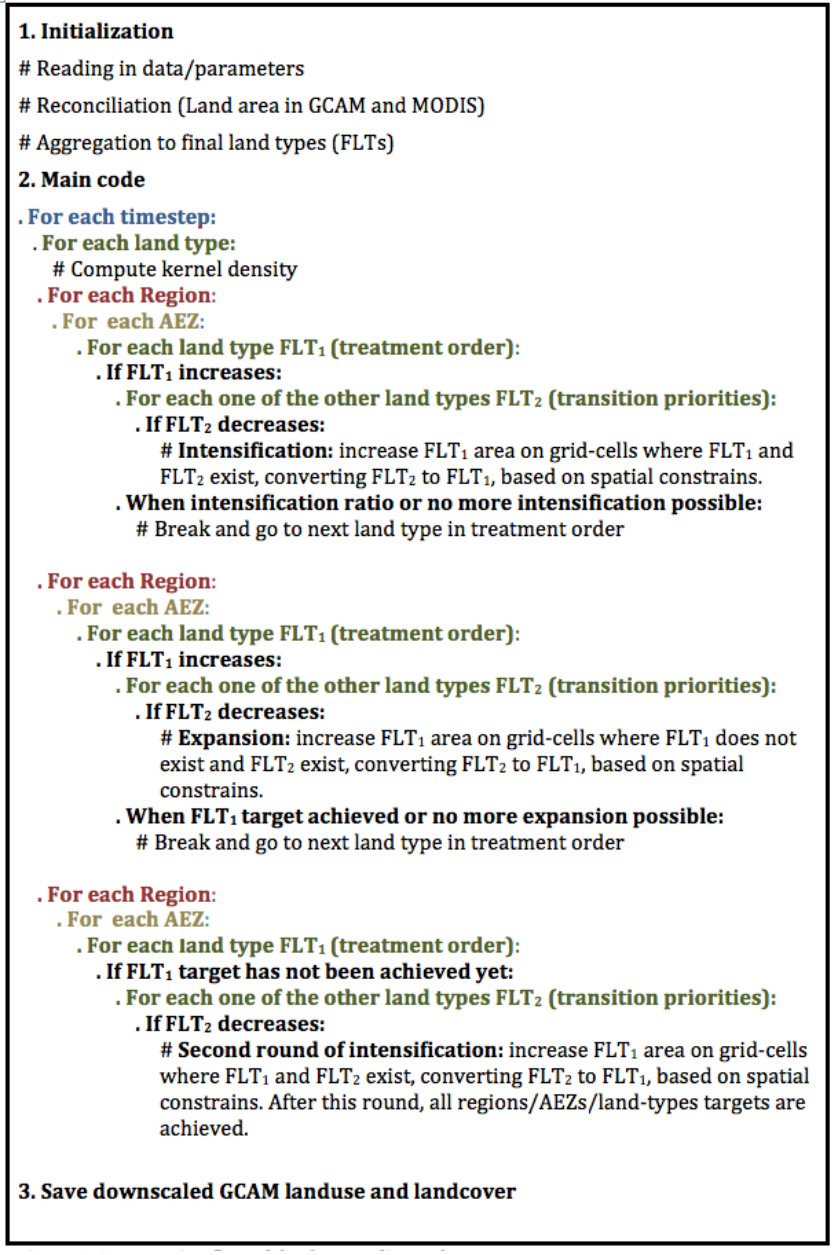

Figure 4. Computation flow of the downscaling code.

achieved after the first computation can be less than $70 \mathrm{~km}^{2}$ while some grid cells might still have grass to spare. The computation is therefore repeated until $70 \mathrm{~km}^{2}$ is reached, or until there are no more grid cells with pre-existing crops and with grass to spare. For this example, we will assume that $60 \mathrm{~km}^{2}$ of grass was converted to crops. The total intensification target being $80,20 \mathrm{~km}^{2}$ has to be done on non-grass areas. The code thus goes to the next crop transition priority (Table 5): shrublands is skipped as it remains unchanged, but forests are projected to decrease by $30 \mathrm{~km}^{2}$. The intensification computation is repeated to convert forests to crops. We will assume that only $7 \mathrm{~km}^{2}$ of forest-to-crop conversion could be achieved. At the end of the intensification, $67 \mathrm{~km}^{2}$ of the projected $100 \mathrm{~km}^{2}$ cropland increase has been allocated, $60 \mathrm{~km}^{2}$ by converting grasslands, $7 \mathrm{~km}^{2}$ by converting forests, leaving $33 \mathrm{~km}^{2}$ to be done by expansion. Of those $33,10 \mathrm{~km}^{2}$ have to replace grasslands as they are projected to decrease by $70 \mathrm{~km}^{2}$ total, 60 of which have been converted by crop intensification. The remaining $23 \mathrm{~km}^{2}$ have to replace forests as they are projected to decrease by $30 \mathrm{~km}^{2}, 7$ of which have been converted by crop intensification.
The expansion function is similar to the intensification function, except that only a fraction of the preselected grid cells are selected to receive the remaining crop area, to avoid patterns of ubiquitous expansion, especially for croplands which generally expand in clusters around newly cultivated lands. Continuing with the applied example, the code goes through the same treatment order and transition priorities, thus first expanding crops into grasslands. Because crop expansion can only occur on grid cells that do not yet have crops, all grid cells in the considered region/AEZ containing grass but not crops are preselected as candidate grid cells to apply the grass conversion to crops. The candidate grid cells are then ranked based on their suitability index. The code selects the most suitable candidate grid cells following a percentage defined by the user (selection threshold, $25 \%$ in the default configuration) or - if stochastic selection is turned on - using the suitability index of each grid cell as the probability it will be selected in a Bernoulli trial. Only the selected grid cells will be used when computing the tentative and actual conversion, in the same way as for intensification. A total of $10 \mathrm{~km}^{2}$ of crops are expanded following this scheme into grasslands, and $23 \mathrm{~km}^{2}$ into forests.

The final intensification ratio is thus $67 / 100=0.67$, less than the user-defined target ( 0.8 in the default configuration) because of a land-driven limitation on the amount of intensification that can be achieved. In other cases, the reverse situation occurs and a larger proportion of LULC change has to be done through intensification, conducted in the second round of intensification (see Fig. 4).

At the end of a full downscaling run, gridded LULC areas are obtained for each of the user-defined land types and for each time step, which can be interpolated to annual data. LULC transitions (the amount of land switched between each pair of land types in each grid cell) are also explicitly tracked by the algorithm given their importance for the carbon cycle (Brovkin et al., 2013). They are, however, not exported by default given their large size and specific format requirements as input for models capable of using them.

\section{Evaluation and sensitivity analysis}

\subsection{Method}

The downscaling code was applied to historical LULC change data with a range of alternative configurations to evaluate how realistic the spatial allocation is and to quantify the sensitivity of the results to the user-defined parameters.

Gridded estimates of historical land use from the HYDE database (version 3.1) were combined to gridded estimates of potential vegetation from the SAGE database to create base-year gridded maps of LULC and region/AEZ aggregated data of LULC change as inputs to the downscaling code. Although the HYDE data include estimates back to $10000 \mathrm{BC}$, we contain the evaluation analysis to the 1700 
2005 period. About $81 \%$ of today's cropland area in the database has been established within that period. Note that HYDE is a reconstruction product and shows substantial deviations from satellite data such as MODIS, but it is used as what we considered the best option to evaluate the downscaling and sensitivity to the parameters, especially due to the temporal span. Using a satellite product directly (e.g., MODIS) would restrain the evaluation to a 10- to 20-year period with much less land use change. The ratio of misclassified over real land use change would also be an issue, for example, with up to an order of magnitude between apparent vs. real change in the MODIS annual land cover product (Friedl et al., 2010).

Six alternative configurations were defined for the $10 \mathrm{pa}-$ rameters shown in Tables 7, 8, and 9. The downscaling was thus run 60 times, each time maintaining the default configuration but changing the value of the considered parameter.

The 2005 downscaled crop distribution was then compared to the HYDE data to compute a performance metric:

$$
\text { metric }=1-\frac{\sum_{\mathrm{gc}}\left|\mathrm{GCAMdc}_{\mathrm{gc}, 2005}-\mathrm{HYDEc}_{\mathrm{gc}, 2005}\right|}{\sum_{\mathrm{gc}}\left|\mathrm{HYDEc}_{\mathrm{gc}, 2005}-\mathrm{HYDEc}_{\mathrm{gc}, \text { byear }}\right|}
$$

where GCAMdc is the downscaled GCAM crop area, HYDEc the crop area in the HYDE data, and byear is the base year of the run (first time step). The metric is computed for single or aggregated regions/AEZs and can vary from -1 to +1 . It represents the fraction of land use change that was allocated to the right grid cells, i.e., in agreement with the land use change computed from HYDE between the base year and 2005. At the extremes, -1 means the downscaling did exactly the opposite to what was observed (decreasing crops where it was supposed to increase and vice versa). A value of +1 is a perfect match. The metric was computed for tropical, temperate, and boreal biomes separately, as delineated in Fig. $1 \mathrm{~b}$ based on the AEZs.

\subsection{Results}

The historical downscaling of LULC change starting from the 1900 base year is presented in Fig. 5. Europe had already acquired most of today's cropland extent by 1900 , but all other regions experienced a substantial increase in cropland area, both in the form of intensification (e.g., India) or expansion (e.g., the corn belt in North America). The downscaling algorithm leads to a spatial 2005 cropland distribution that is in general agreement with the HYDE data, yet lacking their smooth patterns (e.g., North America, India in Fig. 5b, c). However, this smooth aspect seems to be an artifact of the HYDE data when compared to the MODIS data (Figs. 5c and $7 \mathrm{a})$.

The performance metric generally ranges from 0.3 to 0.7 according to the biome and configuration considered (Fig. 6), indicating that the downscaling allocates fairly well
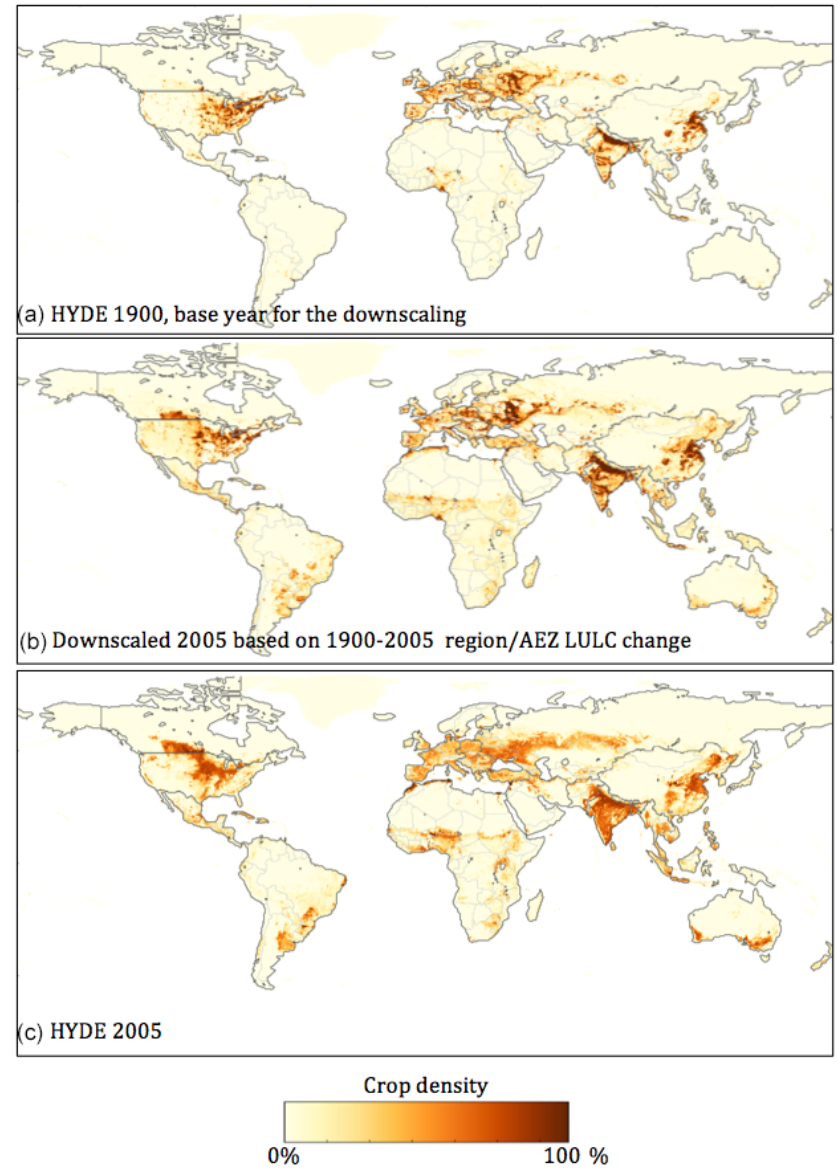

Figure 5. Cropland distribution obtained when downscaling region/AEZ scale land use change from 1900 to 2005 under the basic configuration.

the changes in cropland area (the metric is bound from -1 to 1). Performance and sensitivity to the downscaling parameters are quite different between tropical, temperate and boreal biomes, indicating that LULC dynamics differ and cannot be captured by a single downscaling configuration. Overall, however, sensitivity to the intensification vs. expansion ratio and to the relative contribution of kernel density are the strongest, suggesting the importance of proximity to pre-existing agricultural areas for the allocation of new crops. The performance of the downscaling is also clearly influenced by the base year, especially in the case of tropical regions, and, expectedly, by the aggregation of the output LULC to coarser resolutions.

Performance was also evaluated for the downscaling of forests (Fig. S2), which is a critical aspect for many environmental studies (e.g., carbon cycle, biodiversity). The results are mostly relevant for the tropical biome, where the evaluation shows similar patterns of sensitivity to those of croplands. Both temperate and boreal biomes experienced relatively little forest change from 1900 to 2005 . 
Table 7. Parameters and groups of parameters selected for the sensitivity analysis.

\begin{tabular}{lrrrrrrr}
\hline Parameter & Default value & \multicolumn{5}{c}{ Alternative parameterizations } \\
\cline { 3 - 7 } & & $\mathrm{a}$ & $\mathrm{b}$ & $\mathrm{c}$ & $\mathrm{d}$ & $\mathrm{e}$ & $\mathrm{f}$ \\
\hline intens_ratio & 0.8 & 1 & 0.8 & 0.6 & 0.4 & 0.2 & 0 \\
treatment_order & Table 4 & Table 8 & & & & & \\
transition_priorities & Table 5 & Table 9 & & & & & \\
selection_threshold & $25 \%$ & 5 & 10 & 25 & 50 & 75 & stoch* \\
kernel_density radius & 10 & 2 & 4 & 10 & 25 & 50 & 100 \\
kernel_density constrain contribution & 40 & 0 & 20 & 40 & 60 & 80 & 100 \\
nutrient_availability constrain contribution & 60 & 0 & 20 & 40 & 60 & 80 & 100 \\
soil_workability constrain contribution & 0 & 0 & 20 & 40 & 60 & 80 & 100 \\
base_year & 1800 & 1700 & 1800 & 1900 & 1950 & 1980 & 2000 \\
evaluation resolution & 0.25 & 0.25 & 0.5 & 0.75 & 1 & 2 & 4 \\
\hline
\end{tabular}

* stochastic (see text).
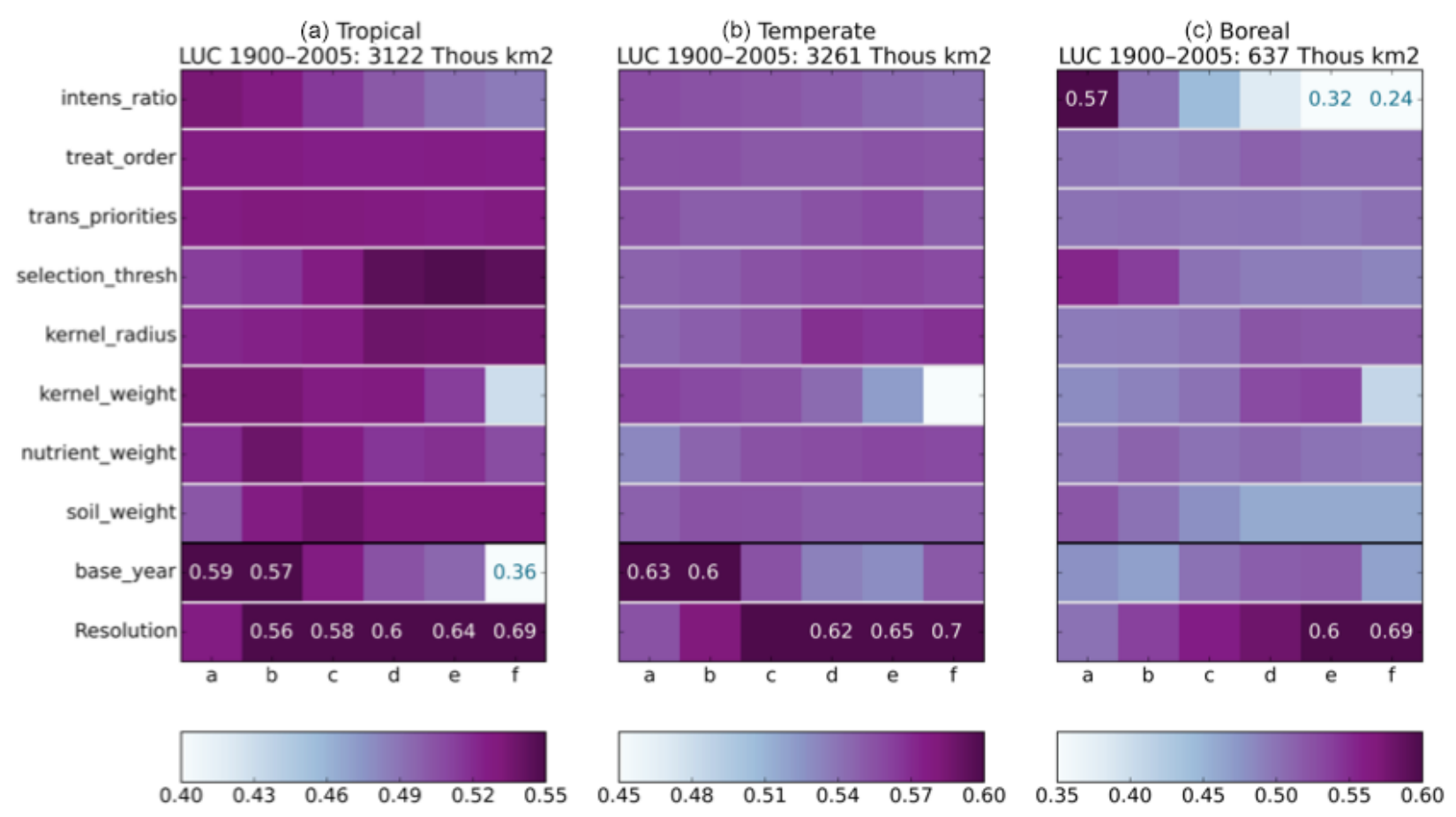

Figure 6. Results of the performance and sensitivity analysis for crops. For the six alternative values ( $x$ axis) of each parameter ( $y$ axis), the color scale indicates the land use downscaling performance metric averaged over all grid cells in the (a) tropical, (b) temperate, and (c) boreal biomes. Colorbar ranges are different for each biome. Beyond-range values are printed in the corresponding $x, y$ position (the full scale of the metric is $[-1,1]$; see text). Note: the figure uses a perceptual colormap with monotically decreasing lightness throughout the colormap. Equal changes in the evaluation metric anywhere are perceived as equal steps in the color space.

\section{Future projections}

\subsection{Objectives and configuration}

We applied the downscaling to two GCAM scenarios of 2005-2100 LULC projections to illustrate the capabilities of the algorithm and its potential applications for environmental impact studies. In the reference scenario, the economy and technological developments are not targeted by any environ- mental policies, thus driving human- and natural-system dynamics in a business-as-usual fashion. This scenario features substantial crop expansion to meet the increasing food demand (growing population, diet changes, etc.). In the Mitigation Policy 4.5 (MP4.5) scenario, an economic policy in the form of a global carbon market applied to industrial, fossilfuel, and terrestrial emissions is implemented to limit radiative forcing in 2100 to $+4.5 \mathrm{~W} \mathrm{~m}^{-2}$. Incentives to carbon sequestration in the MP4.5 lead to afforestation in many re- 


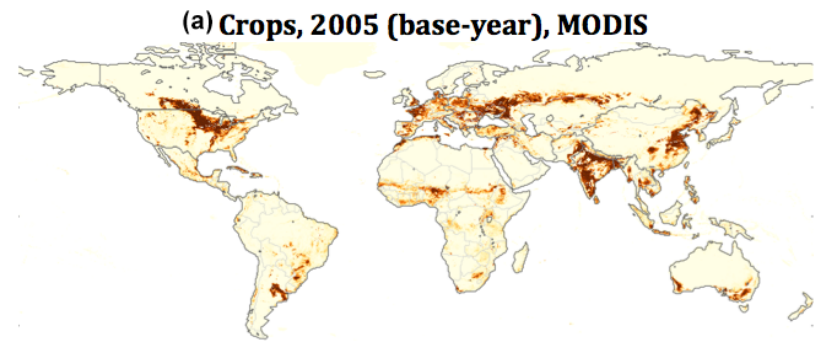

(b) Crop change 2005-2100, Reference scenario

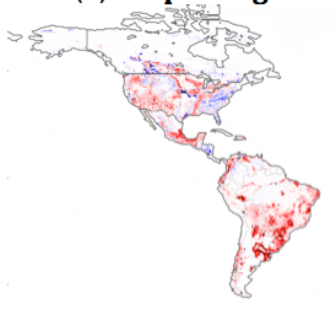

(c) Forest change, 2005-2100, Reference scenario

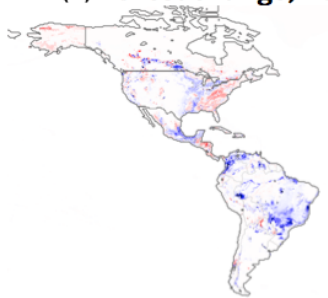

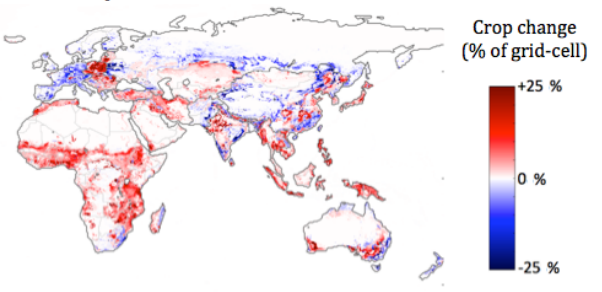
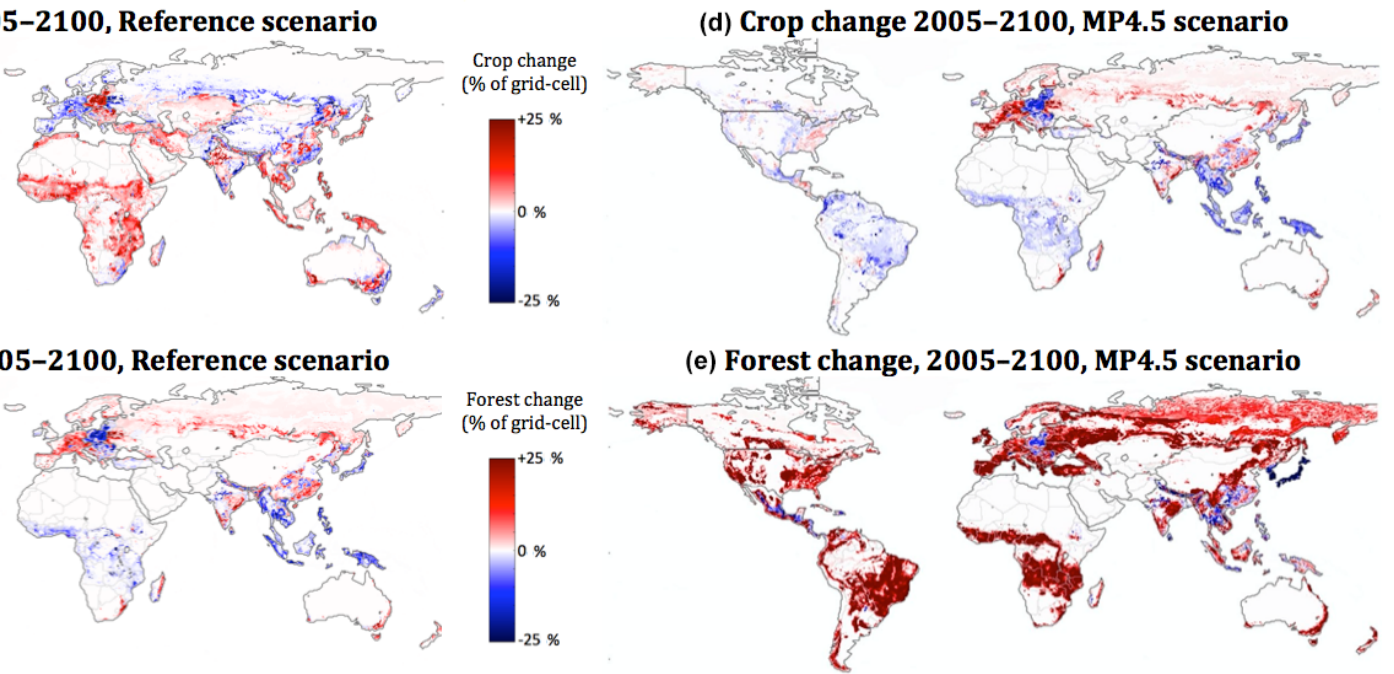

(e) Forest change, 2005-2100, MP4.5 scenario
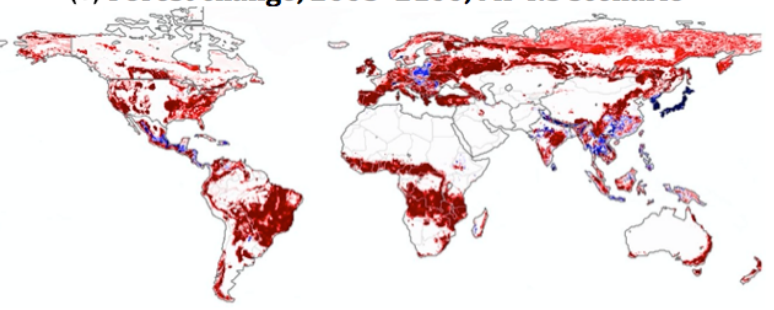

Figure 7. Downscaled GCAM LULC from the reference and MP4.5 scenario.

gions, while agriculture tends to develop in high-yield areas. It is a replicate of the Representative Concentration Pathways 4.5 scenario (RCP4.5) produced by GCAM for the IPCC 5th assessment report (Thomson et al., 2011, p. 4), but instead uses the latest GCAM release (GCAM4).

Contrarily to the historical evaluation analysis that was using HYDE data for the base-year gridded LULC, the projection analysis starts in 2005 with observation-derived MODIS LULC. The downscaling is run with the default configuration presented in Sect. 3.

\subsection{Results}

The downscaled reference and MP4.5 LULC scenarios feature key differences in 2100 due to their specific economic and policy context (Fig. 7). Population reaches about 9 billion in 2060 in GCAM (slowly decreasing thereafter), contributing to increasing food demand that cannot be met with the projected yield improvements on current agricultural areas. As a result, global crop area is projected to increase by $10 \%$ in the reference scenario (2005-2100), with substantial expansion in tropical and subtropical forests (Fig. 7b, c), compensated by afforestation in other regions $(0.3 \%$ deforestation globally). In the MP4.5 scenario, economic incentives for terrestrial carbon sequestration lead to a different solution. Afforestation becomes a profitable option for landowners and global forested area increases by $34 \%$, re- placing agriculture in many regions (Fig. 7d, e). To meet global food demand, agricultural production is intensified in high-yield areas (e.g., India, China) and expands into marginal lands with the support of irrigation and other technological developments (e.g., western U.S., the Middle East). Globally, those changes of agricultural practices enable a reduction of crop area by $10.4 \%$. Note that these general LULC trends are determined by GCAM, including deforestation and afforestation: the downscaling does not make any region/AEZ-scale land use change decision, but instead spatially delineates those decisions to a gridded format. Note also that the downscaled 2005 GCAM crops show much more similar patterns to MODIS than those obtained in the historical evaluation analysis (Fig. 7a vs. Fig. 5b). This is because 2005 was the last year in the evaluation analysis while it is the base year for the projections.

\section{Discussion}

GCAM models human and natural systems at the scale of regions and AEZs, but the LULC downscaling system presented here enables a gridded representation of the land. The gridded outputs are consistent with the GCAM projections and can be influenced with a number of user-defined parameters. The optional spatial constrains provide the capability to adjust the downscaling to capture regional land-use change 
Table 8. Configurations of the treatment order for the sensitivity analysis.

\begin{tabular}{lrlr}
\hline $\begin{array}{l}\text { (a) Final land } \\
\text { types (FLTs) }\end{array}$ & $\begin{array}{r}\text { Treatment } \\
\text { order }\end{array}$ & $\begin{array}{l}\text { (e) Final land } \\
\text { types (FLTs) }\end{array}$ & $\begin{array}{r}\text { Treatment } \\
\text { order }\end{array}$ \\
\hline Forest & 5 & Forest & 3 \\
Shrub & 7 & Shrub & 2 \\
Grass & 6 & Grass & 1 \\
Crops & 4 & Crops & 4 \\
Urban & 1 & Urban & 5 \\
Snow & 2 & Snow & 6 \\
Sparse & 3 & Sparse & 7 \\
\hline (d) Final land & Treatment & (b) Final land & Treatment \\
types (FLTs) & order & types (FLTs) & order \\
\hline Forest & 4 & Forest & 1 \\
Shrub & 6 & Shrub & 3 \\
Grass & 5 & Grass & 2 \\
Crops & 7 & Crops & 4 \\
Urban & 1 & Urban & 5 \\
Snow & 2 & Snow & 6 \\
Sparse & 3 & Sparse & 7 \\
\hline (b) Final land & Treatment & (f) Final land & Treatment \\
types (FLTs) & order & types (FLTs) & order \\
\hline Forest & 2 & Forest & 2 \\
Shrub & 4 & Shrub & 1 \\
Grass & 3 & Grass & 3 \\
Crops & 1 & Crops & 4 \\
Urban & 5 & Urban & 5 \\
Snow & 6 & Snow & 7 \\
Sparse & 7 & Sparse & \\
\hline & & & \\
\hline
\end{tabular}

dynamics. One example illustrated in this study consists in using soil characteristics (i.e., nutrients, workability) to drive the allocation of agricultural activities. The downscaling system was primarily developed as an integrating tool, enabling LULC change impact assessments by providing gridded inputs to other models that cannot be run with the original GCAM data at region/AEZ scale. The gridded outputs may also be used to directly analyze spatial patterns within and between GCAM scenarios, albeit with the understanding that realistic results depend on the chosen configuration for the region, time period and aspects of LULC that are being considered.

Models that might be coupled to GCAM through LULC downscaling all have specific input data requirements - different land types or spatial resolution for example. The downscaling system can be easily adapted to meet a number of these requirements, without any edits to the code. Any number of FLTs can be downscaled provided that baseyear data are available and that parameters specific to each land type are provided (e.g., aggregation rules, transition priorities). For example, in the case of a model requiring separate broadleaf/needleleaf and deciduous/evergreen forest types - for which base-year distribution is readily available in MODIS - Tables 2-6 need to be modified into Tables S2S6 (the Supplement) and all four types of forests will be downscaled. Another example consists in downscaling specific crop types for agricultural models (instead of a single crop category as shown in this study), which requires cropspecific base-year data and modified Tables 2-6. The necessary data and configuration tables are provided as a beta version with the downscaling system (see user manual). Other aspects that are flexible include the downscaling resolution, the spatial domain (e.g., continental, regional focus), and the base-year LULC data (e.g., higher quality regional data sets).

The downscaling method can be used for a number of applications related to LULC change. It contributed to a study assessing global gridded carbon fluxes from agricultural production and consumption (Wolf et al., 2015), by downscaling FAO crop inventory data at the county/state/province level to a $0.05^{\circ}$ grid. It was also applied to downscale specific crop types as well as irrigation practices from a detailed U.S. version of GCAM (Huang et al., 2016) to study the response of terrestrial hydrology to future scenarios of LULC change.

Despite the flexibility, some aspects are intrinsic to the GCAM model and the downscaling code and might be a limitation for certain applications. GCAM models net LULC change within each spatial unit (e.g., region/AEZ), as opposed to gross LULC, and thus minimizes the amount of LULC change from one time step to the other. For example, a crop increase by $100 \mathrm{~km}^{2}$ in a region/AEZ could be the result of several LULC change storylines, including one where crops increase by $150 \mathrm{~km}^{2}$ in some part of the region/AEZ and decrease by $50 \mathrm{~km}^{2}$ elsewhere. In that case, $200 \mathrm{~km}^{2}$ of land are converted (gross change), with consequences for carbon emissions, landscape fragmentation, or the water cycle. The downscaling does not try to model those dynamics a posteriori from the GCAM net land use change. A new version of GCAM is currently being developed to represent land use dynamics annually, which the downscaling algorithm can process. The net vs. gross LULC change issue will be mostly eliminated for these scenarios as multiple land conversions within the same year are rare. The lack of flexibility to account for specific dynamics through the regional and temporal domain of the downscaling is another limitation, which can be addressed with code changes. As shown in the evaluation and sensitivity analysis, regional performances vary depending on the amount and type of observed LULC change and on the period considered. For example, patterns of agricultural expansion into the Amazon forest will be best downscaled under a specific configuration that would be suboptimal to represent intensification and encroachment into semi-arid areas in the U.S. Great Plains. Similarly, that same configuration would not be the best to reproduce the move towards intensification and away from deforestation observed in the Amazon basin since 2004. The parameterization is currently common to all regions and for the entire downscaling period, but can be made flexible with relatively simple edits to the code. 
Table 9. Configurations of the final land types (FLTs) transition priorities for the sensitivity analysis.

\begin{tabular}{|c|c|c|c|c|c|c|c|}
\hline \multirow[t]{2}{*}{ (a) Final land types (FLTs) } & \multicolumn{7}{|c|}{ Final land types (FLTs) for downscaling } \\
\hline & Forest & Shrub & Grass & Crops & Urban & Snow & Sparse \\
\hline Forest & 0 & 1 & 2 & 3 & 4 & 6 & 5 \\
\hline Shrub & 5 & 0 & 4 & 6 & 1 & 3 & 2 \\
\hline Grass & 6 & 5 & 0 & 4 & 1 & 3 & 2 \\
\hline Crops & 4 & 3 & 2 & 0 & 1 & 6 & 5 \\
\hline Urban & 5 & 3 & 2 & 4 & 0 & 6 & 1 \\
\hline Snow & 6 & 5 & 4 & 3 & 2 & 0 & 1 \\
\hline Sparse & 6 & 4 & 2 & 3 & 5 & 1 & 0 \\
\hline \multirow[t]{2}{*}{ (b) Final land types (FLTs) } & \multicolumn{7}{|c|}{ Final land types (FLTs) for downscaling } \\
\hline & Forest & Shrub & Grass & Crops & Urban & Snow & Sparse \\
\hline Forest & 0 & 1 & 2 & 3 & 4 & 6 & 5 \\
\hline Shrub & 5 & 0 & 4 & 6 & 1 & 3 & 2 \\
\hline Grass & 6 & 5 & 0 & 4 & 1 & 3 & 2 \\
\hline Crops & 3 & 2 & 4 & 0 & 1 & 6 & 5 \\
\hline Urban & 5 & 3 & 2 & 4 & 0 & 6 & 1 \\
\hline Snow & 6 & 5 & 4 & 3 & 2 & 0 & 1 \\
\hline Sparse & 6 & 4 & 2 & 3 & 5 & 1 & 0 \\
\hline \multirow[t]{2}{*}{ (c) Final land types (FLTs) } & \multicolumn{7}{|c|}{ Final land types (FLTs) for downscaling } \\
\hline & Forest & Shrub & Grass & Crops & Urban & Snow & Sparse \\
\hline Forest & 0 & 1 & 2 & 3 & 4 & 6 & 5 \\
\hline Shrub & 5 & 0 & 4 & 6 & 1 & 3 & 2 \\
\hline Grass & 6 & 5 & 0 & 4 & 1 & 3 & 2 \\
\hline Crops & 2 & 3 & 4 & 0 & 1 & 6 & 5 \\
\hline Urban & 5 & 3 & 2 & 4 & 0 & 6 & 1 \\
\hline Snow & 6 & 5 & 4 & 3 & 2 & 0 & 1 \\
\hline Sparse & 6 & 4 & 2 & 3 & 5 & 1 & 0 \\
\hline \multirow{2}{*}{ (d) Final land types (FLTs) } & \multicolumn{7}{|c|}{ Final land types (FLTs) for downscaling } \\
\hline & Forest & Shrub & Grass & Crops & Urban & Snow & Sparse \\
\hline Forest & 0 & 3 & 2 & 1 & 4 & 6 & 5 \\
\hline Shrub & 6 & 0 & 5 & 4 & 1 & 3 & 2 \\
\hline Grass & 4 & 5 & 0 & 6 & 1 & 3 & 2 \\
\hline Crops & 4 & 3 & 2 & 0 & 1 & 6 & 5 \\
\hline Urban & 5 & 3 & 2 & 1 & 0 & 6 & 4 \\
\hline Snow & 6 & 5 & 4 & 3 & 2 & 0 & 1 \\
\hline Sparse & 6 & 4 & 2 & 3 & 5 & 1 & 0 \\
\hline \multirow[t]{2}{*}{ (e) Final land types (FLTs) } & \multicolumn{7}{|c|}{ Final land types (FLTs) for downscaling } \\
\hline & Forest & Shrub & Grass & Crops & Urban & Snow & Sparse \\
\hline Forest & 0 & 3 & 1 & 2 & 4 & 6 & 5 \\
\hline Shrub & 4 & 0 & 6 & 5 & 1 & 3 & 2 \\
\hline Grass & 6 & 4 & 0 & 5 & 1 & 3 & 2 \\
\hline Crops & 4 & 3 & 2 & 0 & 1 & 6 & 5 \\
\hline Urban & 5 & 4 & 1 & 2 & 0 & 6 & 3 \\
\hline Snow & 6 & 5 & 4 & 3 & 2 & 0 & 1 \\
\hline Sparse & 6 & 4 & 2 & 3 & 5 & 1 & 0 \\
\hline \multirow[t]{2}{*}{ (f) Final land types (FLTs) } & \multicolumn{7}{|c|}{ Final land types (FLTs) for downscaling } \\
\hline & Forest & Shrub & Grass & Crops & Urban & Snow & Sparse \\
\hline Forest & 0 & 3 & 2 & 1 & 4 & 6 & 5 \\
\hline Shrub & 6 & 0 & 5 & 4 & 1 & 3 & 2 \\
\hline Grass & 4 & 5 & 0 & 6 & 1 & 3 & 2 \\
\hline Crops & 2 & 3 & 4 & 0 & 1 & 6 & 5 \\
\hline Urban & 5 & 3 & 2 & 1 & 0 & 6 & 4 \\
\hline Snow & 6 & 5 & 4 & 3 & 2 & 0 & 1 \\
\hline Sparse & 6 & 4 & 2 & 3 & 5 & 1 & 0 \\
\hline
\end{tabular}




\section{Data availability}

The downscaling system is available on the GitHub opensource software site (https://github.com/JGCRI/GCAMLU). The repository includes the source code (written in Python 2.7) and a detailed user manual, including software/library requirements. A reference LULC scenario is provided as part of the downscaling system, as well as spatial LULC data from MODIS for the 2005 base year. Alternative scenarios can be generated with GCAM, which is available from the Joint Global Change Research Institute (http:// www.globalchange.umd.edu/models/gcam/download/).

\section{The Supplement related to this article is available online at doi:10.5194/gmd-9-3055-2016-supplement.}

Competing interests. The authors declare no competing financial interest.

Author contributions. Yannick Le Page and Tris O. West designed the model. Yannick Le Page developed the model and performed the simulations. Yannick Le Page prepared the manuscript with contributions from all authors.

Acknowledgements. This research was partly supported by the National Aeronautics and Space Administration Carbon Monitoring System and ACCESS programs under projects NNH12AU35I and NNH13AW58I, and the Office of Science of the U.S. Department of Energy under the Integrated Assessment Research Program http://science.energy.gov/. Y. Le Page was also partly supported by a Marie Skłodowska-Curie Individual Fellowships (MSCA-IF2014-EF), project number 659969 (HESFIRE).

Edited by: H. Sato

Reviewed by: two anonymous referees

\section{References}

Brovkin, V., Boysen, L., Arora, V. K., Boisier, J. P., Cadule, P., Chini, L., Claussen, M., Friedlingstein, P., Gayler, V., Van Den Hurk, B., and others: Effect of anthropogenic land-use and landcover changes on climate and land carbon storage in CMIP5 projections for the twenty-first century, J. Climate, 26, 6859-6881, 2013.

Calvin, K., Wise, M., Kyle, P., Patel, P., Clarke, L., and Edmonds, J.: Trade-offs of different land and bioenergy policies on the path to achieving climate targets, Climatic Change, 123, 691-704, doi:10.1007/s10584-013-0897-y, 2014.

Clarke, L., Lurz, J., Wise, M., Edmonds, J., Kim, S., Smith, S., and Pitcher, H.: Model documentation for the minicam climate change science program stabilization scenarios: Ccsp product 2.1 a, Pac. Northwest Natl. Lab. PNNL-16735, 2007.

Ellis, E. C.: Anthropogenic transformation of the terrestrial biosphere, Philos. T. Roy. Soc. A, 369, 1010-1035, doi:10.1098/rsta.2010.0331, 2011.

FAO: FAOSTAT, available at: http://faostat.fao.org/site/348/default. aspx (last access: 8 January 2016), 2010.

Fischer, G., Nachtergaele, F., Prieler, S., Van Velthuizen, H. T., Verelst, L., and Wiberg, D.: Global agro-ecological zones assessment for agriculture (GAEZ 2008), IIASA Laxenburg Austria FAO Rome Italy, 2008.

Foley, J. A., DeFries, R., Asner, G. P., Barford, C., Bonan, G., Carpenter, S. R., Chapin, F. S., Coe, M. T., Daily, G. C., Gibbs, H. K., and Helkowski, J. H.: Global consequences of land use, Science, 309, 570-574, 2005.

Friedl, M. A., Sulla-Menashe, D., Tan, B., Schneider, A., Ramankutty, N., Sibley, A., and Huang, X.: MODIS Collection 5 global land cover: Algorithm refinements and characterization of new datasets, Remote Sens. Environ., 114, 168-182, doi:10.1016/j.rse.2009.08.016, 2010.

Hejazi, M., Edmonds, J., Clarke, L., Kyle, P., Davies, E., Chaturvedi, V., Wise, M., Patel, P., Eom, J., and Calvin, K.: Long-term global water projections using six socioeconomic scenarios in an integrated assessment modeling framework, Technol. Forecast. Soc., 81, 205-226, 2014.

Houghton, R. A., House, J. I., Pongratz, J., van der Werf, G. R., DeFries, R. S., Hansen, M. C., Le Quéré, C., and Ramankutty, N.: Carbon emissions from land use and land-cover change, Biogeosciences, 9, 5125-5142, doi:10.5194/bg-9-5125-2012, 2012.

Huang, M., Leng, G., Le Page, Y., West, T. O., Liu, Y., and Leung, L. R.: Response of terrestrial hydrology over the conterminous US to high-resolution scenarios of climate and land cover/land use changes from 2005 to 2095, Climatic Change, in preparation, 2016.

Hurtt, G., Chini, L., Frolking, S., Betts, R., Feddema, J., Fischer, G., Fisk, J., Hibbard, K., Houghton, R., Janetos, A., and Jones, C. D.: Harmonization of land-use scenarios for the period 1500 2100: 600 years of global gridded annual land-use transitions, wood harvest, and resulting secondary lands, Climatic Change, 1-45, 2011.

Kim, S. H., Edmonds, J., Lurz, J., Smith, S. J., and Wise, M.: The ObjECTS framework for integrated assessment: hybrid modeling of transportation, Energy J., 2, 63-92, 2006.

Klein Goldewijk, K., Beusen, A., Van Drecht, G., and De Vos, M.: The HYDE 3.1 spatially explicit database of human-induced 
global land-use change over the past 12,000 years, Glob. Ecol. Biogeogr., 20, 73-86, 2011.

Kraucunas, I., Clarke, L., Dirks, J., Hathaway, J., Hejazi, M., Hibbard, K., Huang, M., Jin, C., Kintner-Meyer,M., van Dam, K. K., and Leung, R.: Investigating the nexus of climate, energy, water, and land at decision-relevant scales: the Platform for Regional Integrated Modeling and Analysis (PRIMA), Climatic Change, 129, 573-588, 2014.

Kyle, P., Luckow, P., Calvin, K., Emanuel, W., Mayda, N., and Zhou, Y.: GCAM 3.0 Agriculture and Land Use: Data Sources and Methods, available at: http://wiki.umd.edu/gcam/images/ 2/25/GCAM_AgLU_Data_Documentation.pdf (last access: 27 February 2012), 2011.

Le Page, Y., Hurtt, G., Thomson, A. M., Bond-Lamberty, B., Patel, P., Wise, M., Calvin, K., Kyle, P., Clarke, L., Edmonds, J., and Janetos, A.: Sensitivity of climate mitigation strategies to natural disturbances, Environ. Res. Lett., 8, 15018, doi:10.1088/17489326/8/1/015018, 2013.

Mahmood, R., Pielke Sr, R. A., Hubbard, K. G., Niyogi, D., Bonan, G., Lawrence, P., McNider, R., McAlpine, C., Etter, A., Gameda, S., and Qian, B.: Impacts of land use/land cover change on climate and future research priorities, B. Am. Meteorol. Soc., 91, 37-46, 2010.

Monfreda, C., Ramankutty, N., and Hertel, T. W.: Global agricultural land use data for climate change analysis, in: Economic analysis of land use in global climate change policy, edited by: Hertel, T. W., Rose, S. K., and Tol, R. S., chap. 2, 33-48, 2009.

Pachauri, R. K., Allen, M. R., Barros, V. R., Broome, J., Cramer, W., Christ, R., Church, J. A., Clarke, L., Dahe, Q., Dasgupta, P., and Dubash, N. K.: Climate Change 2014: Synthesis Report. Contribution of Working Groups I, II and III to the Fifth Assessment Report of the Intergovernmental Panel on Climate Change, available at: http://epic.awi.de/37530/ (last access: 5 July 2015), 2014.

Pongratz, J., Reick, C. H., Raddatz, T., and Claussen, M.: Biogeophysical versus biogeochemical climate response to historical anthropogenic land cover change, Geophys. Res. Lett., 37, 8, doi:10.1029/2010GL043010, 2010.

Ramankutty, N. and Foley, J. A.: Estimating historical changes in global land cover: Croplands from 1700 to 1992, Global Biogeochem. Cy., 13, 997-1027, 1999a.
Ramankutty, N. and Foley, J. A.: Estimating historical changes in land cover: North American croplands from 1850 to 1992, Global Ecol. Biogeogr., 8, 381-396, 1999b.

Thomson, A. M., Calvin, K. V., Chini, L. P., Hurtt, G., Edmonds, J. A., Bond-Lamberty, B., Frolking, S., Wise, M. A., and Janetos, A. C.: Climate mitigation and the future of tropical landscapes, Proc. Natl. Acad. Sci. USA, 107, 19633-19638, doi:10.1073/pnas.0910467107, 2010.

Thomson, A. M., Calvin, K. V., Smith, S. J., Kyle, G. P., Volke, A., Patel, P., Delgado-Arias, S., Bond-Lamberty, B., Wise, M. A., Clarke, L. E., and Edmonds, J. A.: RCP4.5: a pathway for stabilization of radiative forcing by 2100 , Climatic Change, 109 , 77-94, 2011.

West, T. O., Brandt, C. C., Baskaran, L. M., Hellwinckel, C. M., Mueller, R., Bernacchi, C. J., Bandaru, V., Yang, B., Wilson, B. S., Marland, G., and Nelson, R. G.: Cropland carbon fluxes in the United States: increasing geospatial resolution of inventorybased carbon accounting, Ecol. Appl., 20, 1074-1086, 2010.

West, T. O., Le Page, Y., Huang, M., Wolf, J., and Thomson, A. M.: Downscaling global land cover projections from an integrated assessment model for use in regional analyses: results and evaluation for the US from 2005 to 2095, Environ. Res. Lett., 9, 64004, doi:10.1088/1748-9326/9/6/064004, 2014.

Wise, M. and Calvin, K.: GCAM 3.0 Agriculture and Land Use: Technical Description of Modeling Approach, available at: https://wiki.umd.edu/gcam/images/8/87/ GCAM3AGTechDescript12_5_11.pdf (last access: 27 February 2012), 2011.

Wise, M., Calvin, K., Kyle, P., Luckow, P., and Edmonds, J.: Economic and physical modeling of land use in GCAM 3.0 and an application to agricultural productivity, land, and terrestrial carbon, Climate Change Economics, 5, 1450003, doi:10.1142/S2010007814500031, 2014.

Wolf, J., West, T. O., Le Page, Y., Kyle, G. P., Zhang, X., Collatz, G. J., and Imhoff, M. L.: Biogenic carbon fluxes from global agricultural production and consumption, Global Biogeochem. Cy., 29, 2015GB005119, doi:10.1002/2015GB005119, 2015. 